\title{
Methodology for Reliable Tribological Investigations Applying a Micro Tribometer in Ball-on-Plate Configuration
}

\author{
Florian Böhmermann * and Oltmann Riemer
}

IWT Leibniz Institute for Materials Engineering, Laboratory for Precision Machining, Badgasteiner Straße 3, 28359 Bremen, Germany

\begin{abstract}
Aim of this work is the development of a methodology for reliable tribological investigations when applying a micro tribometer. Experiments were conducted in ball-on-plate configuration with linear reciprocating motion. Two different sphere materials were applied: A199.9 aluminum alloy and 1.4301 austenitic stainless steel. A textured surface from 1.2379 hardened tool steel machined by micro milling exhibiting an areal arithmetic mean height of $\mathrm{Sa}=295 \mathrm{~nm}$ was used as counterpart. The experiments comprised of the investigation of the coefficient of friction and the evolution of the facet area on the spheres in contact with the textured surface depending on the normal load applied and the number of reciprocating cycles. For the early stage of the experiments an ongoing increase of the area of the facet on the spheres was found; occurring friction was manly governed by abrasion of the sphere's material and three-body deformation. This was considered as unstable state of the tribological investigation process, not producing meaningful results. For the later stage equilibrium facet areas on the spheres were found and an ongoing conduction of the tribological experiments did not provoke any increase of their sizes. Here, occurring friction was mainly governed by adhesion. The final facet area on a sphere was directly dependent on the sphere's materials and the applied normal loads. For all subsequent investigations applying a micro tribometer, only spheres exhibiting an equilibrium facet area should be used to gain robust results of tribological investigations, required for the development of e.g. dry deep drawing processes.
\end{abstract}

Keyword: Surface, Texture, Friction

\section{Introduction}

Innovative micro replication techniques such as micro deep drawing allow for the economic mass manufacture of smallest parts fulfilling mechanical functions, and, thus, to cover new market demands. However, miniaturized processes are devoted to size effects. Hu et al. found a reduction of the achievable limit drawing ratio from $\beta=2.0$ to $\beta=1.6$ for the lubricated deep drawing of micro cups from aluminum A199.5 when reducing the punch diameter from $5 \mathrm{~mm}$ to $1 \mathrm{~mm}$. The reduction of the limit drawing ratio was traced back to changes in tribological conditions on microscopic level [1]. Engel related this tribological size effect to the invariance of surface roughness to scaling [2]. This leads to a change in lubrication conditions together with an increase of friction between the die and the work piece during forming. Recent research work focused on the development of dry micro deep drawing processes. A dry conduction of forming processes e.g. allows reducing process steps in production and is associated with major economic and ecological benefits [3]. $\mathrm{Hu}$ et al. successfully performed dry micro deep drawing applying diamond like carbon coated (DLC) forming dies. The work piece material was austenitic stainless steel 1.4301 (X5CrNi18-10); the punch diameter was $1 \mathrm{~mm}$ [4]. The friction reducing properties of DLC coatings was explained by their graphitization on nanometer scale in dependence on velocity of relative motion and applied loads provoking a self-lubricating effect [5]. Shimizu et al investigated the development of the work piece material adhesion to the die surface in successive dry deep drawing experiments against 1.4301 stainless steel foils [6]. Two different punch diameters were applied: $0.85 \mathrm{~mm}$ and $5.1 \mathrm{~mm}$. Distinctively reduced adhesive wear was found for the experiments applying the smaller diameter punch, what was explained with the relative short sliding length in geometrically downscaled deep drawing processes. The researchers also introduced an analytical friction model to generally describe the size effect in friction for dry micro deep drawing [7]. The model was based on that of Bhushan and Nosonovski but was extended about the conditions of downscaled micro strip drawing tests against phosphor bronze foil [8]. The model showed good agreement with the results from the actual strip drawing experiments. Furthermore, Shimizu et al. in their work confirmed the scale dependence of the plowing component contributing to the overall friction force. A decrease of friction was found for geometrically downscaled strip drawing experiments. This was be explained with the lower probability of particles abraded from the work piece dwelling at the die-work piece interface. Micro textured forming die surfaces can 
support the forming process by controlling the frictional behavior, especially under dry conditions. Brinksmeier et al. demonstrated the tribological function of micro textured surfaces generated by raster micro milling with ball-endmills in strip drawing tests under dry conditions [9]. Compared to polished reference $(\mathrm{Sa}=30 \mathrm{~nm})$, a $20 \%$ reduced coefficient of friction was found for selected micro textured samples exhibiting an arithmetical mean height $\mathrm{Sa}$ of $200 \mathrm{~nm}$ to $400 \mathrm{~nm}$. The design of such deterministic surface textures generated by micro milling is primarily determined by the properties of the machined material, the cutting strategy (up- or down-milling), and the machining parameters width of cut $a_{e}$ and feed per tooth $f_{z}[10]$. The transfer of micro textured surfaces to tribologically adapted forming dies is highly desirable, especially for dry forming tasks. The major advantage when applying micro milling is the potential to manufacture the forming die's geometry and the tribological active micro textured surfaces in one process step. A first attempt towards micro textured forming dies was presented by Böhmermann and Riemer [11]. However, the identification of most suitable micro textured surfaces characterized by areal roughness parameters according to ISO 25178 standard still remains a research topic. Even though strip drawing tests are suitable for necessary tribological investigations, they suffer from time consuming preparation for each single test. The application of a micro tribometer instead can significantly reduce the testing time. However, friction experiments conducted with these delicate instruments under the use of comparably low normal forces $(10 \mathrm{mN}$ to several hundreds of $\mathrm{mN})$ are prone to noise and also misinterpretation by the operator.

Aim of this work is the development of a methodology for reliable tribological investigation when applying a micro tribometer. Experiments are carried out in ball-on-plate configuration with reciprocating motion observing the evolution of the coefficient of friction and the facet area on the spheres due to wear in dependence on the number of cycles. Results of the investigations are one key step in design process for textured micro deep drawing dies, suitable for dry forming.

\section{Experimental section}

\subsection{Micro tribometer}

The instrument applied in the tribological investigations was a Tetra BASALT MUST micro tribometer in ballon-plate configuration. The relative motion between the sphere and the sample surface is provided by the reciprocating movement of a motorized stage that carries the sample. The instrument allows for the simultaneous recording of the normal force $\mathrm{F}_{\mathrm{N}}$ applied and the friction force $F_{R}$ as a result of the relative motion of sphere and surface under test, at which $F_{N}$ and $F_{R}$ are indirectly determined by deflection measurement of a cantilever (double leaf spring design, fixed position and rotation) using fiber optical sensors. The cantilever is characterized by spring rates of $1200 \mathrm{~N} / \mathrm{m}$ in normal direction $\left(F_{N}\right)$ and $1200 \mathrm{~N} / \mathrm{m}$ in tangential direction $\left(F_{R}\right)$, respectively. The normal load $\mathrm{F}_{\mathrm{N}}$ applied can be set in a range of $1 \mathrm{mN}$ to $600 \mathrm{mN}$, the measurement range of the friction force $F_{R}$ is $\pm 300 \mathrm{mN}$. The resolution for the measurement of the normal force and the friction force is given by the manufacturer with $0.36 \mu \mathrm{N}$. The maximum stroke length for tribological testing in ball-on-plate configuration is $1_{\max }=10 \mathrm{~mm}$; the maximum speed of the reciprocating motion is $\mathrm{V}_{\text {lin, } \max }=10 \mathrm{~mm} / \mathrm{s}$. An overview of the general setup is given in Figure 1.

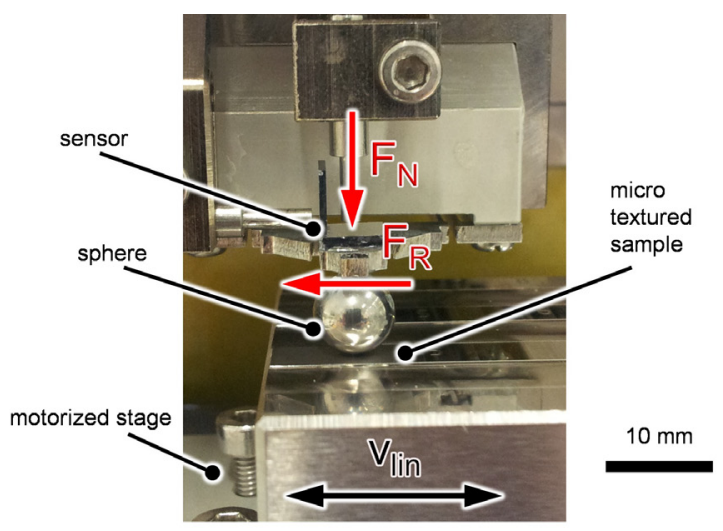

Fig. 1. Ball-on-plate setup for frictional testing on a Tetra BASALT MUST micro tribometer (in accordance with Ref. [11]).

\subsection{Textured sample}

The textured sample for tribological investigations was made from 1.2379 (X153CrMoV12) hardened tool steel with a hardness of $60 \mathrm{HRC} \pm 0.6 \mathrm{HRC}$. The texture was generated by micro milling using a $1.5 \mathrm{~mm}$ diameter ball-endmill; the cutting strategy was down milling. The feed velocity $v_{f}$, the rotational speed $n$, the cutting depth $a_{p}$ and the width of cut $a_{e}$ were set at $v_{f}=600 \mathrm{~mm} / \mathrm{min}$, $\mathrm{n}=25,500 \mathrm{~min}^{-1}, \quad \mathrm{a}_{\mathrm{p}}=0.06 \mathrm{~mm}$ and $\mathrm{a}_{\mathrm{e}}=0.03 \mathrm{~mm}$, respectively. Subsequently, the machined surface was measured by a Sensofar Plu 2300 optical profilometer. The raw data were processed by an image processor (Scanning Probe Image Processor, SPIPTM) to derive areal roughness parameters according to ISO 25178 standard (cut-off $\lambda_{\mathrm{s}}=0.25 \mu \mathrm{m}$, cut-off $\lambda_{\mathrm{c}}=0.08 \mathrm{~mm}$ ).

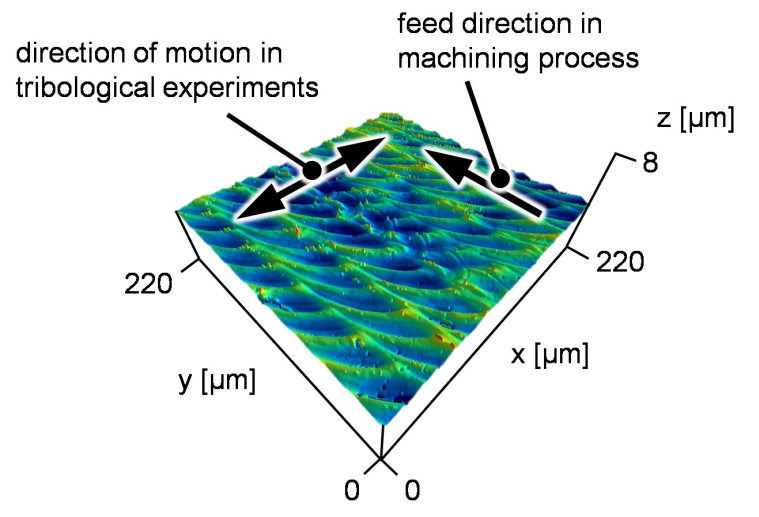

Fig. 2. Surface plot of the textured sample applied in tribological testing. 
The arithmetical mean height of the surface was found to be $\mathrm{Sa}=295 \mathrm{~nm}$. This textured surface applied in the tribological investigations is representative for a class of micro structured or textured surfaces, known for their friction reducing properties in dry frictional contact under moderate loads [9]. A plot of the textured surface is given in Figure 2.

\subsection{Experimental procedure}

The experiments were conducted in ball-on-plate configuration with linear reciprocating motion. The selected stroke length 1 for all experiments was $4 \mathrm{~mm}$; the speed $v_{l i n}$ of the reciprocating motion was set at $4 \mathrm{~mm} / \mathrm{s}$. All experiments were conducted under dry conditions; both, the spheres and the textured sample surface were thoroughly cleaned using isopropyl alcohol before every single experiment. The testing direction with respect to the micro textured surface was orthogonal to the feed direction of the micro milling process, compare Figure 2. The normal force $\mathrm{F}_{\mathrm{N}}$ and the resulting friction force $F_{R}$ were continuously recorded by the instrument at a sampling rate of 100 data points for each forward and backward motion. The average coefficient of friction $\mu$ as well as the maximum and minimum deviation was automatically calculated from the collected data for each cycle.

A new sphere of $5 \mathrm{~mm}$ in diameter was used for every single experiment. The spheres were attached to the cantilever by bonding using cyanoacrylate adhesive. Two different sphere materials were investigated: A199.9 aluminum alloy (hereafter notated: $\mathrm{Al}$ ) and 1.4301 austenitic stainless steel (X5CrNi18-10, hereafter notated: St). Furthermore, the applied normal force $\mathrm{F}_{\mathrm{N}}$ was varied at $15 \mathrm{mN}, 40 \mathrm{mN}, 70 \mathrm{mN}$, and $100 \mathrm{mN}$, respectively.

The wear induced evolution of the facet area $A_{f}$ on the spheres was determined in dependence on the number of cycles $\mathrm{n}$ by graphic evaluation from microscopy images. For the microscopic investigation the whole cantilever including the sphere was dismounted from the micro tribometer in order to maintain the orientation of the facet area on the sphere relatively to the sample surface. The actual facet area $A_{f}$ was calculated from the mean of the smallest diameter $d_{1}$ and the diameter $d_{2}$ perpendicular to $d_{1}$ detected from the microscopy images in accordance with DIN EN 1071-13 standard, compare Figure 3.

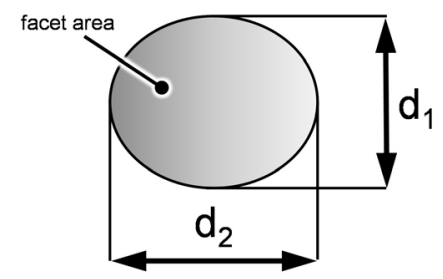

$$
\begin{aligned}
& \bar{d}=\frac{d_{1}+d_{2}}{2} \\
& A_{f}=\frac{1}{4} \pi \bar{d}^{2}
\end{aligned}
$$

Fig. 3. Sketch of facet area and procedure for facet area determination.

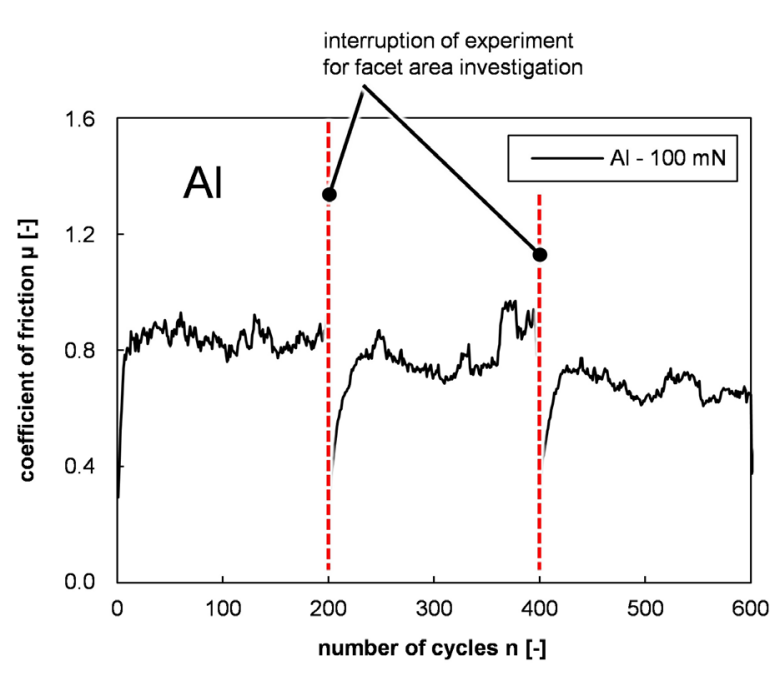

Fig. 4. Coefficient of friction in dependence on the number of cycles $n$ (backward motion only) for the exemplary experiment applying an aluminum A199.9 ball and a normal force of $\mathrm{F}_{\mathrm{N}}=100 \mathrm{mN}$.

The actual pressure per unit area $\mathrm{p}$ was calculated from the facet area $A_{f}$ and the normal load $F_{N}$ applied in the experiments. Usually, this procedure was carried out in steps of $n=200$ cycles, compare Figure 4. The step width was broadened for experiments at advanced stages. Furthermore, the step width was increased to $n=600$ cycles for the testing of the steel spheres, based on the experience gained from the testing of aluminum spheres. For the continuation of an experiment the cantilever was mounted again to the micro tribometer. Once a steady state of the facet area was detected, the experiment was terminated.

\section{Results}

\subsection{Aluminum spheres}

Figure 5 shows the development of the coefficient of friction $\mu$ for the experiment applying an A199.9 aluminum alloy sphere and a normal force $F_{N}$ of $100 \mathrm{mN}$, starting from cycle 400 after the interruption for facet area investigation. For advancing numbers of cycles, the coefficient of friction increased until reaching equilibrium at about $\mu=0.8$, usually after ten to 20 cycles. All experiments using the aluminum spheres were subjected to stick slip, what is pictured by the distinct error bars indicating the minimum and maximum values of the coefficient of friction $\mu$ for each cycle. Figure 6 shows exemplary the evolution of the facet area $\mathrm{A}_{\mathrm{f}}$ on an A199.9 sphere applied in the tribological experiment with a normal load of $100 \mathrm{mN}$ after $\mathrm{n}=600$, 1200 , and 1500 cycles. The investigation of the facet areas on the spheres throughout the experiments generally revealed an increase of the areas towards advancing numbers of cycles. Equilibrium of the facet area $A_{f}$ was reached after about 1000 to 1500 cycles for normal forces $F_{\mathrm{N}}$ of $15 \mathrm{mN}, 40 \mathrm{mN}$, and $100 \mathrm{mN}$, compare Figure 7 a). 

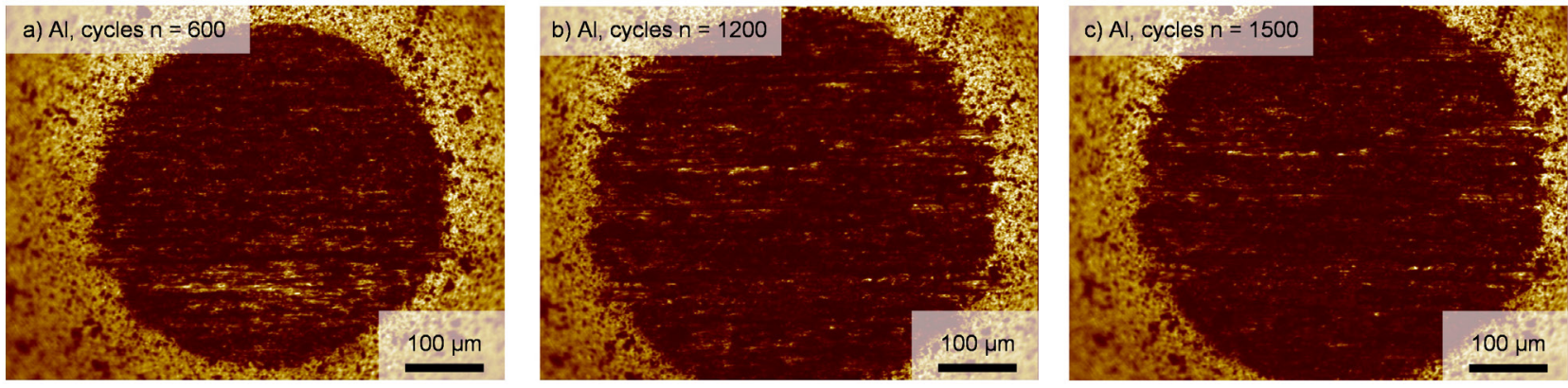

Fig. 6. Microscopic images of the facet areas on an Al99.9 aluminum alloy sphere for the experiment with an applied normal force $\mathrm{F}_{\mathrm{N}}$ of $100 \mathrm{mN}$; a) after 600 cycles, b) after 1200 cycles, and c) after 1500 cycles.

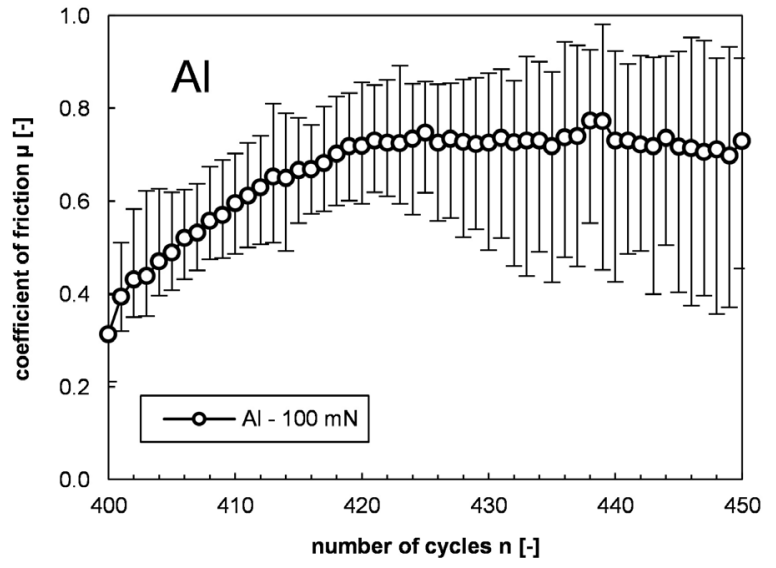

Fig. 5. Coefficient of friction $\mu$ and maximum and minimum deviation recorded in the experiment applying an A199.9 aluminum alloy sphere and a normal force of $F_{\mathrm{N}}=100 \mathrm{mN}$ in dependence on the number of cycles $n$ (backward motion only).

Ongoing conduction of the tribological experiments did not provoke any further increase of the size of the facet area. The equilibrium state for the experiment with a normal load of $70 \mathrm{mN}$ was reached after about 2000 cycles. The results of the facet area investigation in dependence on the number of cycles for all experiments applying A199.9 aluminum alloy spheres are summarized in Figure 7 a). After the determination of the facet areas the actual pressures per unit area were calculated taking the normal force $\mathrm{F}_{\mathrm{N}}$ into account. With exception of the experiment conducted with a normal load of $\mathrm{F}_{\mathrm{N}}=40 \mathrm{mN}$, the equilibrium pressure for all experiments was found to be about $0.0005 \mathrm{~N} / \mathrm{mm}^{2}$ to $0.0007 \mathrm{~N} / \mathrm{mm}^{2}$. The results of the calculation are summed up in Figure $7 \mathrm{~b}$ ).

\subsection{Austenitic stainless steel spheres}

The exemplary development of the coefficient of friction $\mu$ for the experiment applying a 1.4301 austenitic stainless steel sphere and a normal force $F_{N}$ of $100 \mathrm{mN}$ is shown in Figure 8, beginning from cycle 1200 after the interruption for facet area investigation. Similar to those experiments conducted with aluminum spheres, the coefficient of friction increases within the first couple of cycles and reaches equilibrium after five to ten cycles. The experiments were also subjected to stick slip, but less distinct. Those characteristics were found for all
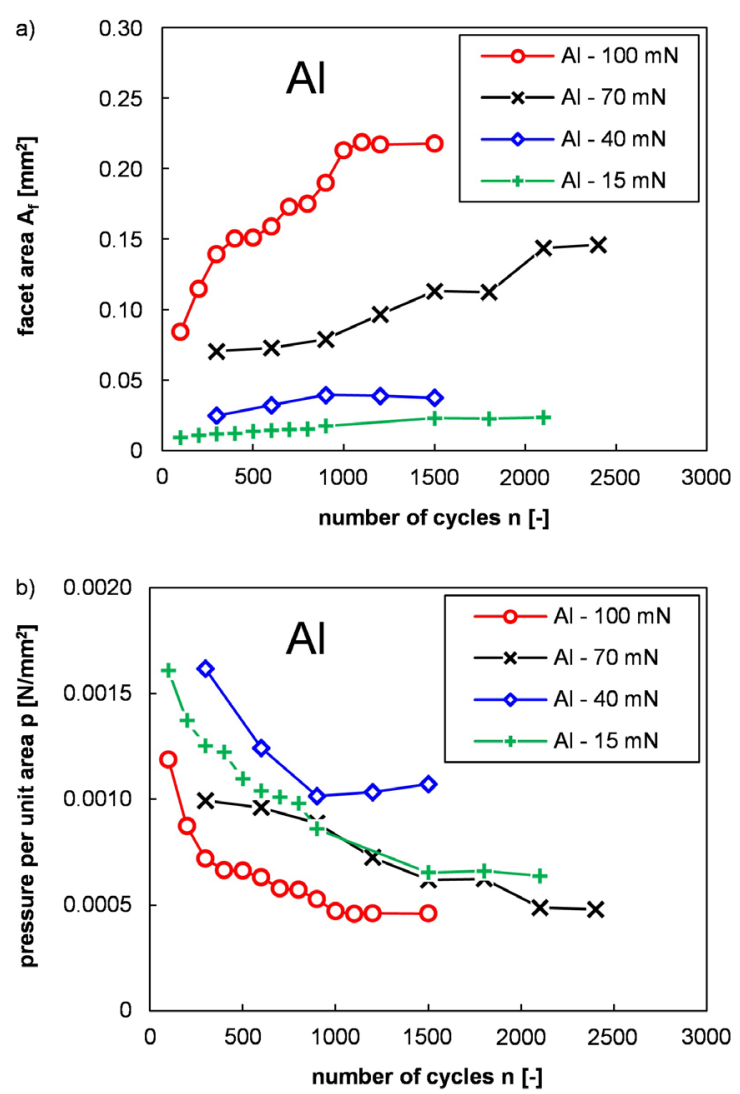

Fig. 7. a) Evolution of the facet area $A_{f}$, and b) the pressure per unit area $p$ in dependence on the number of cycles $n$ for the experiments applying A199.9 spheres.

experiments, regardless of the predetermined normal force $\mathrm{F}_{\mathrm{N}}$. Furthermore, it was found that the absolute values of the coefficient of friction recorded during the experiments applying steel spheres - usually not exceeding $\mu=0.6$ - are generally lower than those recorded for the experiments with the A199.9 spheres. The exemplary evolution of the facet area on a steel sphere (normal force $\mathrm{F}_{\mathrm{N}}=100 \mathrm{mN}$ ) in dependence on the number of cycles is given in Figure 9. Again, the establishment of equilibrium in facet area was found after an increase of the facet area with increasing number of cycles. Other than for the aluminum spheres, this state was reached after about $n=1800$ cycles. Furthermore, the absolute sizes of the facets' areas on the steel spheres are generally smaller than those on the aluminum spheres. The results of the facet area investigation in 

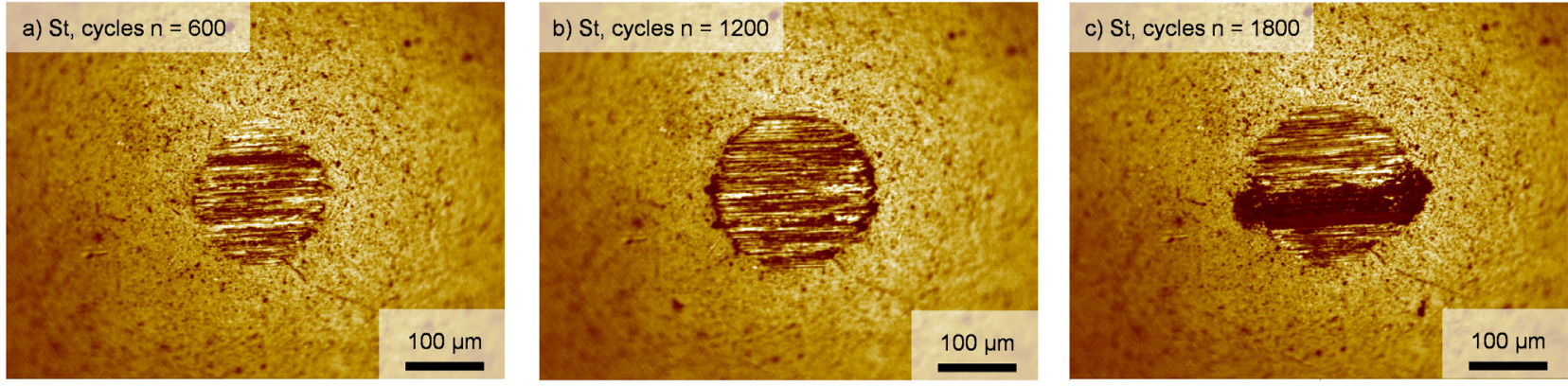

Fig. 9. Microscopic images of the facet areas on an 1.4301 austenitic stainless steel sphere for the experiment with an applied normal force $\mathrm{F}_{\mathrm{N}}$ of $100 \mathrm{mN}$; a) after 600 cycles, b) after 1200 cycles, and c) after 1800 cycles.

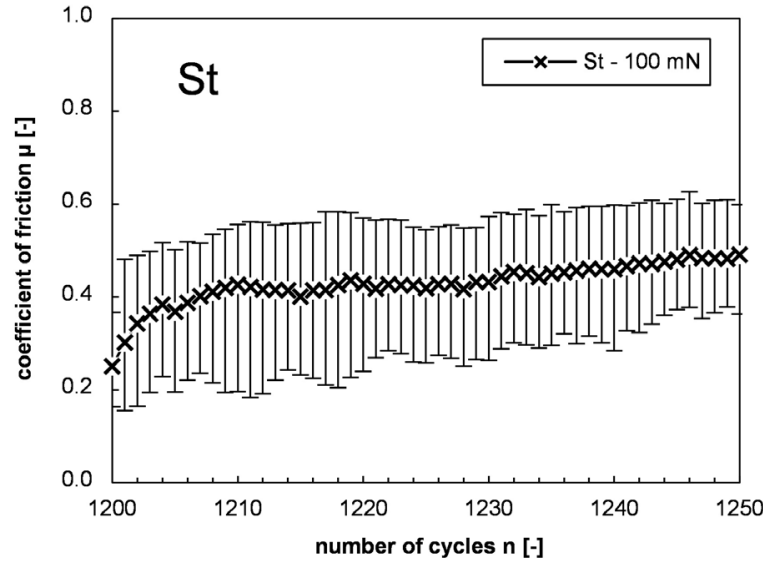

Fig. 8. Coefficient of friction $\mu$ and maximum and minimum deviation recorded in the experiment applying a 1.4301 stainless steel sphere and a normal force of $\mathrm{F}_{\mathrm{N}}=100 \mathrm{mN}$ in dependence on the number of cycles n (backward motion only).

dependence on the number of cycles for all experiments applying 1.4301 stainless steel spheres are summarized in Figure 10 a). The actual pressures per unit area were calculated from the determined facet area $\mathrm{A}_{\mathrm{f}}$ and the normal force $F_{\mathrm{N}}$. The results of the calculation in dependence on the number of cycles are displayed in Figure $10 \mathrm{~b}$ ). Here, similar characteristics as in the experiments with the A199.9 aluminum alloy spheres were found, but generally showing greater numbers of pressure per unit area, coinciding with the smaller facet area.

\section{Discussion}

Tribological experiments using a micro tribometer in ball-on-plate configuration were conducted and the coefficients of friction as well as the evolution of the facet areas on the spheres were investigated throughout the experiments. For both types of spheres - A199.9 aluminum alloy and 1.4301 austenitic stainless steel similar characteristics were found for both, the development of coefficient of friction and the evolution of the facet area on the spheres. It is obvious that at the start of every new experiment there was only point contact between the sphere and the textured surface. This is associated with distinct pressures per unit area enforcing the immediate abrasion of the spheres material
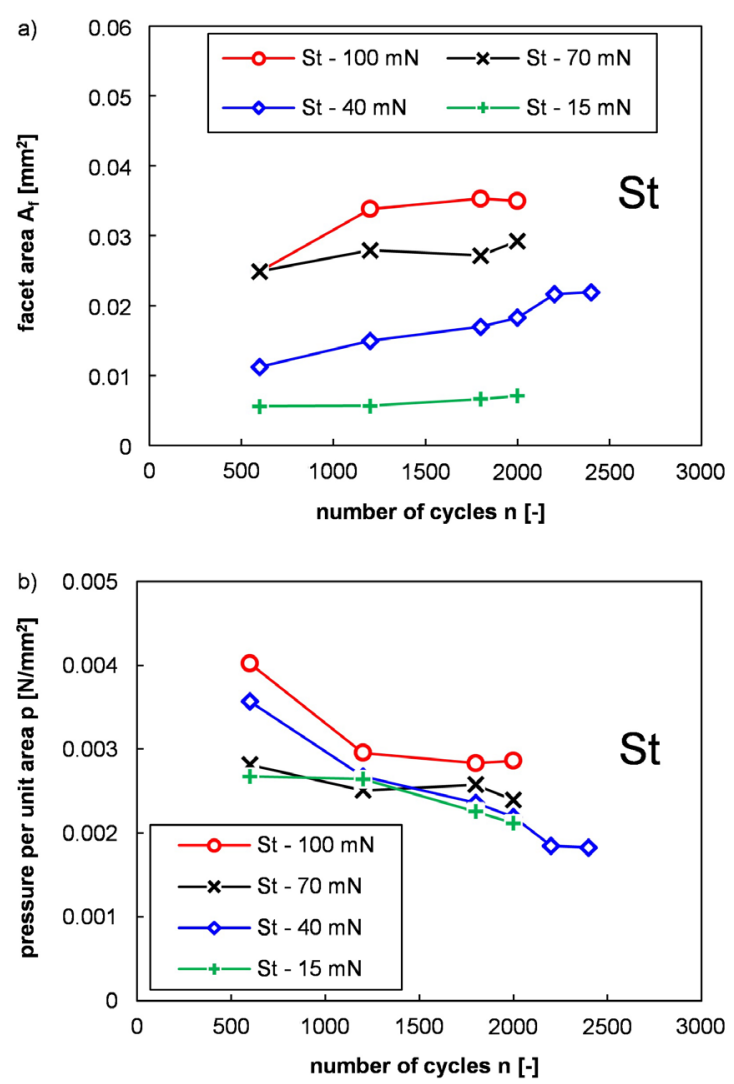

Fig. 10. a) Evolution of the facet area $A_{f}$, and b) the pressure per unit area $\mathrm{p}$ in dependence on the number of cycles $\mathrm{n}$ for the experiments applying 1.4301 stainless steel spheres.

at the onset of relative motion and leading to the formation of a facet area. Subsequently, the contact conditions between the sphere and the textured surface changed from point to areal contact (formation of an interface). For later stages of the experiments, respectively after every investigation of the facet area, the pressure per unit area was still adequate to provoke sufficient elastic and plastic penetration of the textured surfaces' asperities into the softer sphere material. Relative motion between both the tribological partners in contact lead to plowing and cutting type wear on the spheres, compare work of Kayaba et al. [12]. As a result, wear debris was generated, trapped at the interface between sphere and textured surface. Wear particles are generally subjected to strain hardening thus contributing 
to plowing and cutting into the soft sphere material during the experiment. This process is referred as threebody plowing, compare work of Bhushan and Nosonovski [8]. The occurrence of three-body deformation is reflected in the distinct increase of the coefficient of friction for the first couple of cycles after continuation of the conducted experiments. At a stage, where friction is predominantly governed by abrasion of the sphere's material and three-body deformation, the tribological investigation process is considered unstable. No meaningful results can be obtained when tribological testing is conducted under such conditions. For later stages of the experiments - after about 1200 cycles for aluminum spheres and 1800 cycles for steel spheres equilibrium facet areas were found. A further conduction of the experiments did not provoke any further increase of the facet area's sizes. It is assumed that friction now is predominantly governed by adhesion; a stable state of the tribological investigation process was reached. This allows for reliable tribological testing when applying a micro tribometer, i.e. the determination of the impact of adhesion to friction, which is of major concern for the development of dry micro deep drawing processes.

\section{Conclusion}

Fresh spheres applied in tribological investigations using a micro tribometer in ball-on-plate configuration are generally subject to wear, forming a facet area. At this initial stage the setup is not suitable for reliable tribological investigation, due to the strong dependence of the coefficient of friction on changing wear and friction mechanisms, e.g. three-body plowing. For later stages, after the execution of greater numbers of cycles, equilibrium of facet areas establishes at which the final size of the facet area is directly dependent on the sphere's material and the applied normal force. It is assumed that friction now is predominantly governed by adhesion. Reliable tribological investigations can be carried out under these preconditions as no further changes in the contact conditions between sphere and the sample surface will occur. It can be concluded, that reliable tribological investigations applying a micro tribometer require for the preparation of the spheres in order to provide equilibrium facet areas. This should be achieved by a run-in procedure. The actual pressures per unit area for equilibrium facet areas derived from the experiments shown in this work can be applied as control values. These were $p=0.0005 \mathrm{~N} / \mathrm{mm}^{2}$ for A199.9 aluminum alloy spheres and $\mathrm{p}=0.002 \mathrm{~N} / \mathrm{mm}^{2}$ for 1.4301 austenitic stainless steel spheres. The presented methodology can now be applied to the comprehensive tribological investigation of micro textured surfaces by using a micro tribometer in ball-on-plate configuration.

Acknowledgements: The authors would like to thank the German Research Foundation (Deutsche Forschungsgemeinschaft "DFG") for funding this work within sub-project C2 "Surface Optimization" of the Collaborative Research Centre 747 "Micro Cold Forming - Processes, Characterisation, Optimisation" at the University of Bremen. Furthermore, the authors would like to express their greatest thanks to Ms. Juelie Fritsch for the support in conducting the tribological experiments.

\section{References}

1. Z. Hu, R. Walther, F. Vollertsen, Influence of Size Effects on the Process Window for Deep Drawing, Proceedings of the International Deep Drawing Research Group IDDRG International Conference 28 (2009) 785-796

2. U. Engel, Tribology in microforming, Wear 2603 (2006) 265-273

3. F. Vollertsen, F. Schmidt, Dry Metal Forming: Definition, Chances and Challenges, International Journal of Precision Engineering and Manufacturing-Green Technology 11 (2014) 59-62

4. Z. Hu, A. Schubnov, F. Vollertsen, Tribological behaviour of DLC-films and their application in micro deep drawing, Journal of Materials Processing Technology 212 (2012) 647-652

5. Y. Liu, A. Erdemir, E. Meletis, An Investigation of the Relationship between Graphitization and Frictional Behavior of DLC Coatings, Surface and Coatings Technology 86-87 (1996) 564-568

6. T. Shimizu, Y. Murashige, S. Iwaoka, M. Yang, K.I. Manabe, Scale Dependence of Adhesion Behavior under Dry Friction in Progressive Micro-Deep Drawing, Journal of Solid Mechanics and Materials Engineering 72 (2013) 251-263

7. T. Shimizu, M.Yang, K.I. Manabe, Classification of mesoscopic tribological properties under dry sliding friction for microforming operation, Wear 330-331 (2015) 49-58

8. B. Bhushan, M. Nosonovski, Comprehensive model for scale effects in friction due to adhesion and twoand three-body deformation (plowing), Acta Materialia 52 (2004) 2461-2474

9. E. Brinksmeier, O. Riemer, S. Twardy, Tribological behavior of micro structured surfaces for micro forming tools, International Journal of Machine Tools and Manufacture 504 (2010) 425-430

10. E. Brinksmeier, O. Riemer, S. Twardy, Surface Analysis of Micro Sphere End Milled Cold Work Tool Steels, Proceedings of the International Conference on Nanomanufacturing 2 (2010) 173177

11. F. Böhmermann, O. Riemer, Tribological Performance of Textured Micro Forming Dies, Dry Metal Forming OAJ FMT 2 (2016) 067-071

12. T. Kayaba, K. Hokkirigawa, K. Kato, Analysis of the abrasive wear mechanism by successive observations of wear processes in a scanning electron microscope, Wear 110 (1986) 419-430 